\title{
Closure of the sternum with anchoring of the steel wires: Systematic review and meta-analysis
}

Karin Franco Pinotti, MD, Fellow PhD, ${ }^{a}$ Daniele C. Cataneo, MD, PhD, ${ }^{a, b}$

Olavo Ribeiro Rodrigues, MD, PhD, ${ }^{\mathrm{a}, \mathrm{c}}$ and Antônio J. M. Cataneo, MD, $\mathrm{PhD}^{\mathrm{a}, \mathrm{b}}$

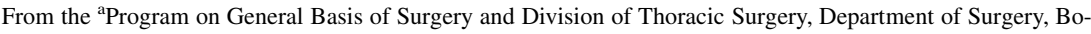
tucatu School of Medicine, São Paulo State University, UNESP, São Paulo, Brazil; bepartment of Surgery, Botucatu School of Medicine, São Paulo State University, UNESP, São Paulo, Brazil; and ${ }^{\mathrm{c}}$ Department of Surgery, Mogi das Cruzes University, São Paulo, Brazil.

Received for publication Oct 25, 2017; revisions received Jan 30, 2018; accepted for publication Feb 11, 2018; available ahead of print March 20, 2018.

Address for reprints: Antônio J. M. Cataneo, MD, PhD, Division of Thoracic Surgery, Department of Surgery, Botucatu School of Medicine, São Paulo State University, UNESP, São Paulo, Brazil, CEP 18.618-970, Botucatu, SP, Brazil (E-mail: acataneo@fmb.unesp.br).

J Thorac Cardiovasc Surg 2018;156:178-86

$0022-5223 / \$ 36.00$

Copyright (c) 2018 by The American Association for Thoracic Surgery

https://doi.org/10.1016/j.jtcvs.2018.02.033

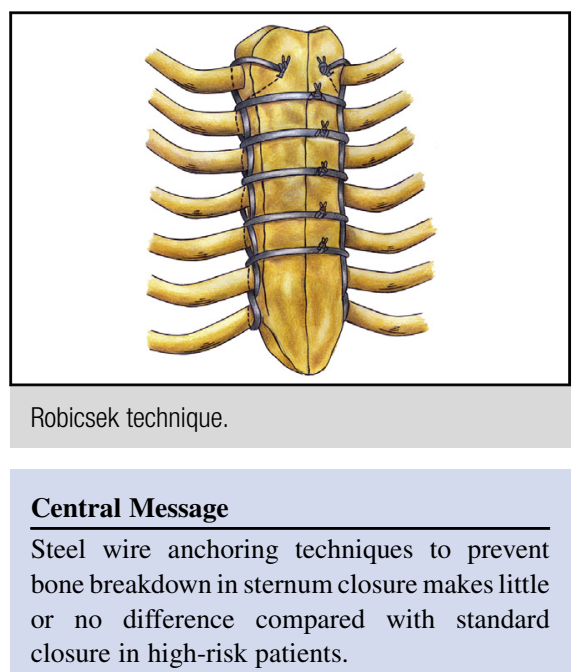

Video clip is available online.

Standard closure after median sternotomy reapproximates the sternum using steel wires with a simple suture technique or figure of 8 configuration (Video 1). However, this closure technique has been associated with several serious complications that have prompted surgeons to look for new closure methods. These complications include sternal instability, dehiscence, and mediastinitis as a result of bone nonconsolidation or bone disruption caused by steel wires. These conditions represent the major causes of morbidity and mortality after cardiac surgery. ${ }^{1}$ Infection rates after median sternotomy vary from $0.2 \%$ to $10 \%$, and in cases of infection, morbidity, and mortality, rates vary from $5 \%$ to $25 \%$. $^{2}$ The incidence of postoperative complications is more frequent with the following risk factors: thoracic radiation, obesity, diabetes, osteoporosis, chronic lung disease, immunosuppression, renal failure, hypertension, advancing age, and chronic use of corticosteroids. ${ }^{3-6}$ New strategies for the closure of median sternotomies are being sought to minimize the incidence of complications. However, an optimal technique has yet to be established. ${ }^{7,8}$ Several alternative methods have been developed. Some are based on the anchoring of the steel wires to prevent rupture of the sternal bone. The first method, described in $1977,{ }^{9}$ consists of passing parasternal continuous wire suture alternately in front of and behind the costal cartilages, leaving them within the usual parasternal sutures (Figure 1, A). This technique can be simplified: the steel wires placed on both sides of the sternum, anterior, and posterior in the alternating costal cartilages, so that both ends of the wire
Perspective

Nonstandard closure is more expensive and time-consuming. Therefore, because it is shown to make nonsignificant difference, a standard closure should be preferred when resources and time are limited.

See Editorial Commentary page 187. are drawn out from the cranial ends and the caudal ends of the sternum, so that later the caudal and cranial tips of each side can be tied. Then 6 wires can be passed around the parasternal weave and secured ${ }^{10}$ (Figure 1, B). Another technique uses staplers: The metal staplers are placed longitudinally in the sternum, serving as an anchor to prevent the transverse steel wires from cutting the sternum. ${ }^{11}$ Other techniques using different devices to avoid dehiscence of the sternum have been used: titanium plate, titanium double-foot hook system, nitinol thermos reactive clips, Kirschner wires, biocompatible adhesives, and others. All of these alternative closure methods have the disadvantage of being more labor-intensive than the standard method, consequently increasing the surgical time and cost of the intervention.

Because isolated randomized controlled trials (RCTs) have less power in estimating the effect of treatment, we decided to conduct a systematic review to test whether the combination of several RCTs would show a difference between interventions. The objective of this review was to evaluate the effects of steel wire anchoring techniques to 


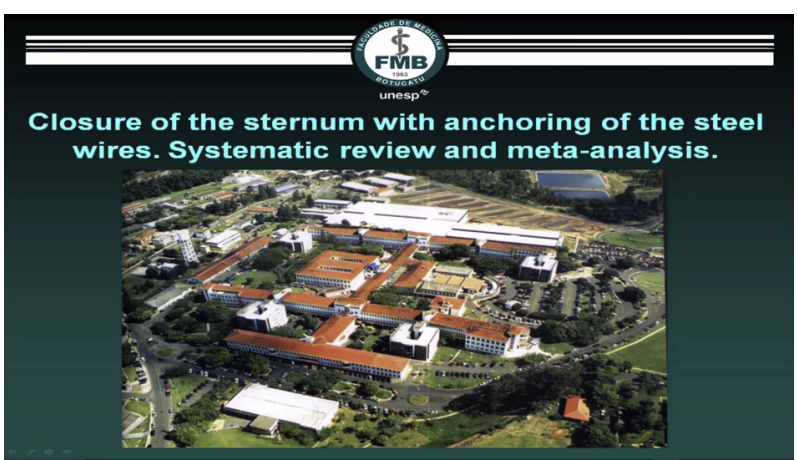

VIDEO 1. Closure of the sternum with anchoring of the steel wires. Systematic review and meta-analysis. Video available at: http://www. jtcvsonline.org/article/S0022-5223(18)30396-9/fulltext.

prevent bone rupture and other complications of sternal wound after sternotomy in people with risk factors.

\section{MATERIALS AND METHODS}

\section{Criteria for Considering Studies for the Review}

\section{Studies: RCTs.}

Participants: Adults who underwent median sternotomy, regardless of gender or race with risk factors (thoracic radiation, obesity, diabetes, osteoporosis, chronic lung disease, immunosuppression, renal failure, hypertension, advancing age, and chronic use of corticosteroids).

Interventions: Techniques of sternal closure based on the anchoring of steel wires to prevent disruption of the sternal bone (nonstandard closure).

Control: Conventional sternal closure (ie, simple suture or figure of 8 configuration).

Primary outcomes: Deep sternal wound infection and superficial wound infection. Both were measured by clinical history, physical examination, and microbiological analysis of mediastinal or superficial tissue or fluid, or image techniques.

Secondary outcomes: All-cause mortality, whether or not related to deep wound infection, sternal instability (noninfective) measured by clinical history, physical examination or image techniques, mediastinitis detected by clinical and image techniques, or purulent discharge from the mediastinum, length of hospital stay, reoperation related to deep wound infection, mechanical ventilation time, duration of stay in the intensive care unit, and chest pain.

\section{Search Methods for Identification of Studies}

Electronic searching: Ovid MEDLINE (1946 to present); EMBASE (1966 to present); LILACS (1982 to present), the Cochrane Central Register of Controlled Trials (CENTRAL) (The Cochrane Library) (latest issue); date of search: June 6, 2017.

We used the search strategy in Medline: (Sternotomies OR (Median Sternotomy) OR (Median Sternotomies) OR (sternal wounds) OR (sternal wound)) AND ((Closure techniques) OR (Closure technique) OR (Closure methods) OR (Closure method) OR (Wound Closure) OR (Wound Closure Technique) OR (Wound Closure Techniques) OR (Wound Closure methods) OR (Wound Closure method) OR (Surgical Closure Techniques) OR (Surgical Closure Technique) OR (Surgical Closure methods) OR (Surgical Closure Method)).

We adapted this strategy to search The Cochrane Central Register of Controlled Trials (CENTRAL), Lilacs, and EMBASE. The studies were not restricted by language, date of publication, or setting.

The trial database was searched: ClinicalTrials.gov (http://www. clinicaltrials.gov/http://www.clinicaltrials.gov/).

Searching other resources: We checked the reference lists of all relevant studies for additional relevant citations. We contacted the study authors, experts, and manufacturers to identify unpublished data.

\section{Data Collection and Analysis}

Selection of studies: Two independent authors screened the trials identified by the literature search. They resolved disagreements by consulting each other, as well as another review author, regarding quality assurance of the review processes. After this initial assessment, the same authors obtained full versions of articles that appeared to match the inclusion criteria. They deleted duplicate publications that had been identified from different electronic databases.

Data extraction and management: Two authors extracted data and resolved any discrepancies by discussion. The authors used a standard data extraction form to obtain the following information: characteristics of the study (design, methods of randomization); participants (number, age, setting, inclusion and exclusion criteria); interventions; outcomes (types of outcome measures, adverse events). They then checked for errors before entering the data into the review writing software, Review Manager 5.3.

Assessment of risk of bias in included studies: We assessed study quality by using the "risk of bias" tool for Cochrane reviews. ${ }^{12}$ We used the 6 separate criteria and graded each according to the standards.

Measures of treatment effect: For dichotomous data, we used the risk ratio $(\mathrm{RR})$ as the effect measure with $95 \%$ confidence intervals (CIs). For continuous data, we presented the results as mean differences with $95 \% \mathrm{CI}$. When pooling data across studies, we estimated
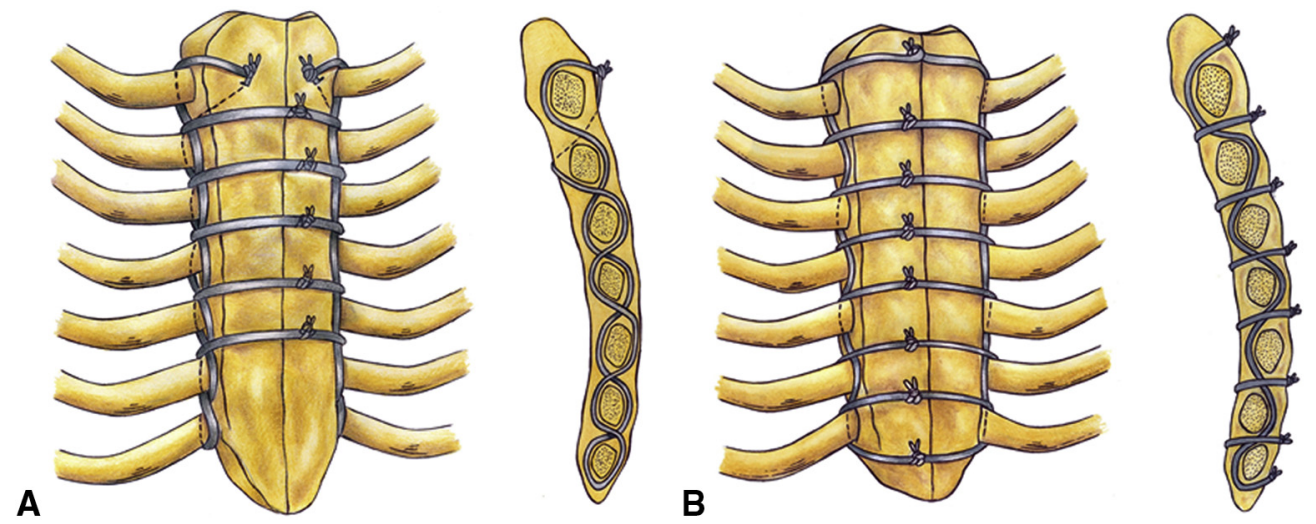

FIGURE 1. Robicsek technique (A) and Robicsek modified (B). 
TABLE 1. Summary of the 7 studies included in the present review

\begin{tabular}{|c|c|c|c|c|c|c|c|}
\hline Author (year) & $\begin{array}{c}\text { Aykut and } \\
\text { colleagues } \\
(\mathbf{2 0 1 1})^{15} \\
\end{array}$ & $\begin{array}{c}\text { Iriz and } \\
\text { colleagues } \\
(2007)^{16} \\
\end{array}$ & $\begin{array}{c}\text { Narang and } \\
\text { colleagues } \\
(2009)^{17} \\
\end{array}$ & $\begin{array}{c}\text { Okutan and } \\
\text { colleagues } \\
(2005)^{11} \\
\end{array}$ & $\begin{array}{c}\text { Schimmer and } \\
\text { colleagues } \\
(\mathbf{2 0 0 8})^{18} \\
\end{array}$ & $\begin{array}{c}\text { Schimmer and } \\
\text { colleagues } \\
(\mathbf{2 0 0 8})^{19} \\
\end{array}$ & $\begin{array}{c}\text { Sharma and } \\
\text { colleagues } \\
(2004)^{10} \\
\end{array}$ \\
\hline Country & Turkey & Turkey & Italy & Turkey & Germany & Germany & India \\
\hline Design study & RCT & $\mathrm{RCT}$ & quasi RCT & RCT & $\mathrm{RCT}$ & RCT & quasi RCT \\
\hline Center (multi/single) & Single & Single & Single & Multi & Multi & Single & Single \\
\hline Period study & 2008-2009 & 2004-2005 & 2004-2007 & 200-2001 & 2006-2007 & $2005-2006$ & 1996-2002 \\
\hline Follow-up & $12 \mathrm{mo}$ & $3 \mathrm{mo}$ & $14-26 \mathrm{mo}$ & Not reported & $3 \mathrm{mo}$ & Not reported & Not reported \\
\hline Participants & 150 & 71 & 200 & 40 & 815 & 86 & 776 \\
\hline Interventions & $\begin{array}{l}\text { Figure of } 8 \\
\text { X Robicsek }\end{array}$ & $\begin{array}{c}\text { Figure of } 8 \text { or } \\
\text { single wire } \\
\text { X Robicsek } \\
\text { modified }\end{array}$ & $\begin{array}{l}\text { Standard } \\
\text { closure X } \\
\text { Robicsek }\end{array}$ & $\begin{array}{l}\text { Standard } \\
\quad \text { closure X } \\
\text { staplers }\end{array}$ & $\begin{array}{l}\text { Standard } \\
\text { closure X } \\
\text { Robicsek }\end{array}$ & $\begin{array}{l}\text { Standard } \\
\text { closure X } \\
\text { Robicsek }\end{array}$ & $\begin{array}{l}\text { Standard } \\
\text { closure X } \\
\text { Robicsek } \\
\text { modified }\end{array}$ \\
\hline \multicolumn{8}{|l|}{ Risk of bias } \\
\hline $\begin{array}{l}\text { Random sequence } \\
\text { generation }\end{array}$ & Unclear & Low & High & Unclear & Low & Unclear & High \\
\hline $\begin{array}{l}\text { Allocation } \\
\text { concealment }\end{array}$ & Unclear & Unclear & High & Unclear & Unclear & Unclear & High \\
\hline $\begin{array}{l}\text { Blinding participants } \\
\text { and personnel }\end{array}$ & Unclear & High & Unclear & Unclear & Unclear & Unclear & Unclear \\
\hline $\begin{array}{l}\text { Blinding outcome } \\
\text { assessment }\end{array}$ & Unclear & High & Low & Unclear & Unclear & Unclear & Unclear \\
\hline $\begin{array}{l}\text { Incomplete outcome } \\
\text { data }\end{array}$ & Low & Low & Low & Unclear & Low & Unclear & Low \\
\hline Selective reporting & Low & Low & Low & Unclear & Low & Low & Low \\
\hline
\end{tabular}

$R C T$, Randomized clinical trial.

the mean difference if the outcomes were measured in the same way across trials. We had intended to use the standardized mean difference to combine trials that measured the same outcome, but used different methods.

Assessment of heterogeneity: We looked for clinical heterogeneity by examining the study details and then tested for statistical heterogeneity between trial results using the chi-square test and the heterogeneity value $\left(\mathrm{I}^{2}\right)$. We considered a $P$ value of .1 as significant. ${ }^{13}$ We considered the presence of substantial heterogeneity when $\mathrm{I}^{2}$ was greater than $75 \%$, and in this case the combination should be considered inappropriate, and the results should be presented in narrative form.

Data synthesis: We analyzed the data using RevMan 5.3 software provided by the Cochrane Collaboration. We used a fixed-effect model for meta-analysis in the absence of clinical, methodological, and statistical heterogeneity. In addition, if the $\mathrm{I}^{2}$ was greater than zero, we applied a random-effects model to discern whether the conclusions differed, and any difference was noted. If pooling was not possible or appropriate, we presented a narrative summary. ${ }^{13}$

We used the principles of the GRADE system to assess the strength of evidence of the body of evidence associated with specific outcomes in our review and constructed a summary of findings using the GRADE software. ${ }^{14}$

\section{RESULTS}

Results of the search: The search strategy identified 1616 titles. After removal of the duplicate references, there were 1488 titles, and 1437 were excluded. After assessment of 51 full-text articles, 44 were excluded. Fifteen studies were excluded because they were retrospective or nonrandomized; 4 studies were congress abstracts, 2 were review articles, and 3 were about cosmetic treatments of scars. Twenty studies were excluded because they used other surgical interventions to avoid complications after sternotomy. Therefore, 7 RCTs that met the minimal methodological requirements were considered for inclusion in this review (Figure 2).

Included studies: Seven studies were included in this review, ${ }^{10,11,15-19}$ with a total of 2138 participants. All included studies claimed to be RCTs; 3 were undertaken in Europe, ${ }^{17-19} 3$ were performed in Eurasia, ${ }^{11,15,16}$ and 1 was performed in Asia ${ }^{10}$ (Table 1).

Participants and duration of trials: All studies included both male and female patients with mean age ranging from $56.5 \pm 9.3$ years to $77.0 \pm 14.0$ years. All studies analyzed participants with 1 or more risk factors for sternal wound complications undergoing cardiac surgery. Followup periods ranged from 3 to 16 months in 4 studies and were not reported in 3 studies. . $^{10,11,19}$

Types of intervention: Seven studies randomized patients to standard sternal closure (figure of 8 or simple transversal suture) against the closure based on the anchoring of the steel wires to prevent disruption of the sternal bone, Robicsek original or modified, ${ }^{10,15-19}$ or stapler. ${ }^{11}$ 
Patient or population: adults who underwent median sternotomy with risk factors

Settings: hospital (tertiary care)

Intervention: Techniques of sternal closure based on the anchoring of the steel wires

Comparison: conventional sternal closure

\begin{tabular}{|c|c|c|c|c|c|}
\hline \multirow[b]{2}{*}{ Outcomes } & \multicolumn{2}{|c|}{ Illustrative comparative risks $(95 \% \mathrm{CI})^{*}$} & \multirow[b]{2}{*}{$\begin{array}{l}\text { Relative effect } \\
(95 \% \text { CI })\end{array}$} & \multirow[b]{2}{*}{$\begin{array}{c}\text { No. of participants } \\
\text { (studies) }\end{array}$} & \multirow{2}{*}{$\begin{array}{l}\text { Quality of the } \\
\text { evidence } \\
\text { (GRADE) }\end{array}$} \\
\hline & $\frac{\text { Assumed risk }}{\text { [control }]}$ & $\begin{array}{c}\text { Corresponding risk } \\
\text { [experimental] }\end{array}$ & & & \\
\hline \multirow{2}{*}{$\begin{array}{l}\text { Deep sternal wound infection } \\
\text { [follow-up] 3-16 mo }\end{array}$} & High-risk population & & RR $0.42(0.11-1.59)$ & $1936(6)$ & $\oplus \oplus$ Low $\dagger, \ddagger$ \\
\hline & 23 per 1000 & 10 per $1000(2.5-37)$ & & & \\
\hline \multirow{2}{*}{$\begin{array}{l}\text { Superficial wound infection } \\
\text { [follow-up] 3-16 mo }\end{array}$} & High-risk population & & RR $1.38(0.83-2.30)$ & $1076(4)$ & $\oplus \oplus \oplus$ Moderate $\dagger$ \\
\hline & 44 per 1000 & 61 per $1000(37-101)$ & & & \\
\hline \multirow[t]{2}{*}{ Death [follow-up] 3-16 mo } & High-risk population & & RR $0.93(0.47-1.84)$ & $1210(5)$ & $\oplus \oplus \oplus$ Moderate $\dagger$ \\
\hline & 27 per 1000 & 25 per $1000(13-50)$ & & & \\
\hline \multirow{2}{*}{$\begin{array}{l}\text { Mediastinitis [follow-up] } \\
\text { 3-16 mo }\end{array}$} & High-risk population & & RR $0.74(0.17-3.16)$ & $1197(4)$ & $\oplus \oplus \oplus$ Moderate $\dagger$ \\
\hline & 8 per 1000 & 6 per $1000(1-25)$ & & & \\
\hline \multirow{2}{*}{$\begin{array}{l}\text { Reoperation [follow-up] } \\
\text { 3-16 mo }\end{array}$} & High-risk population & & RR $0.82(0.34-1.98)$ & $434(3)$ & $\oplus \oplus \oplus$ Moderate $\dagger$ \\
\hline & 46 per 1000 & 38 per $1000(16-83)$ & & & \\
\hline
\end{tabular}

GRADE Working Group grades of evidence High quality: Further research is very unlikely to change our confidence in the estimate of effect. Moderate quality: Further research is likely to have an important impact on our confidence in the estimate of effect and may change the estimate. Low quality: Further research is very likely to have an important impact on our confidence in the estimate of effect and is likely to change the estimate. Very low quality: We are very uncertain about the estimate. $C I$, Confidence interval; $R R$, risk ratio. *The basis for the assumed risk (eg, the median control group risk across studies) is provided in the next 2 footnotes. The corresponding risk (and its $95 \% \mathrm{CI}$ ) is based on the assumed risk in the comparison group and the relative effect of the intervention (and its $95 \% \mathrm{CI}$ ). $\dagger$ Downgraded because of selection bias and detection bias. $\ddagger$ Downgraded because of inconsistency.

Types of outcomes: Of the 7 studies included, 6 assessed the incidence of deep sternal wound infection, ${ }^{10,11,15,16,18,19}$ 5 assessed sternal instability (without infection), ${ }^{10,11,15,17,18}$ 5 assessed death, ${ }^{11,16-19} 4$ assessed superficial wound infection, ${ }^{11,15,16,18} 4$ assessed hospital stay, ${ }^{11,16,18,19} 4$ assessed mediastinitis, ${ }^{10,15-17} 3$ assessed reoperation, ${ }^{15,17,19}$ 2 assessed mechanical ventilation time, ${ }^{18,19} 1$ assessed intensive care unit stay, ${ }^{18}$ and 1 assessed pain. ${ }^{19}$

\section{Risk of Bias in Included Studies}

Allocation (selection bias): Three studies ${ }^{11,15,19}$ did not report random sequence generation and allocation concealment, and therefore they were ranked as unclear risk of bias for this domain. Two studies ${ }^{16,18}$ used computer-generated random sequence or shuffled cards (low risk of bias), but they did not report allocation concealment (unclear risk). In 2 studies, the type of intervention depended on the unit where the patient was being treated ${ }^{17}$ or by including each patient in turn to an intervention or other intervention $^{10}$; therefore, they were ranked as high risk of bias for this domain.

Blinding (performance bias and detection bias): Five studies did not report the blinding of participants, personnel, and outcome assessment; therefore, they were ranked as unclear risk of bias for this domain. ${ }^{10,11,15,18,19}$ One study was ranked as high risk of performance and detection bias because clinicians were not blinded, patients were not reported, and there was no blinding of outcomes assessment. ${ }^{16}$ One study did not report the blinding of participants and personnel, but investigators of outcomes were blinded, and therefore they were ranked as unclear risk for performance bias and low risk for detection bias. ${ }^{17}$

Incomplete outcome data (attrition bias): Five studies were ranked as low risk (no evidence of attrition bias). ${ }^{10,15-18}$ Two studies were ranked as unclear risk because no late results were presented in the report ${ }^{11}$ and patients had been excluded without the reason being cited. ${ }^{19}$

Selective reporting (reporting bias): Six studies were ranked as low risk because there was no evidence of selective reporting. ${ }^{10,15-19}$ One study was ranked as unclear risk because no late results were presented in the report. ${ }^{11}$

Other potential sources of bias: We judged all included trials to be free of any other potential sources of bias.

\section{Effects of Interventions: Primary Outcomes}

1. Deep sternal wound infection 

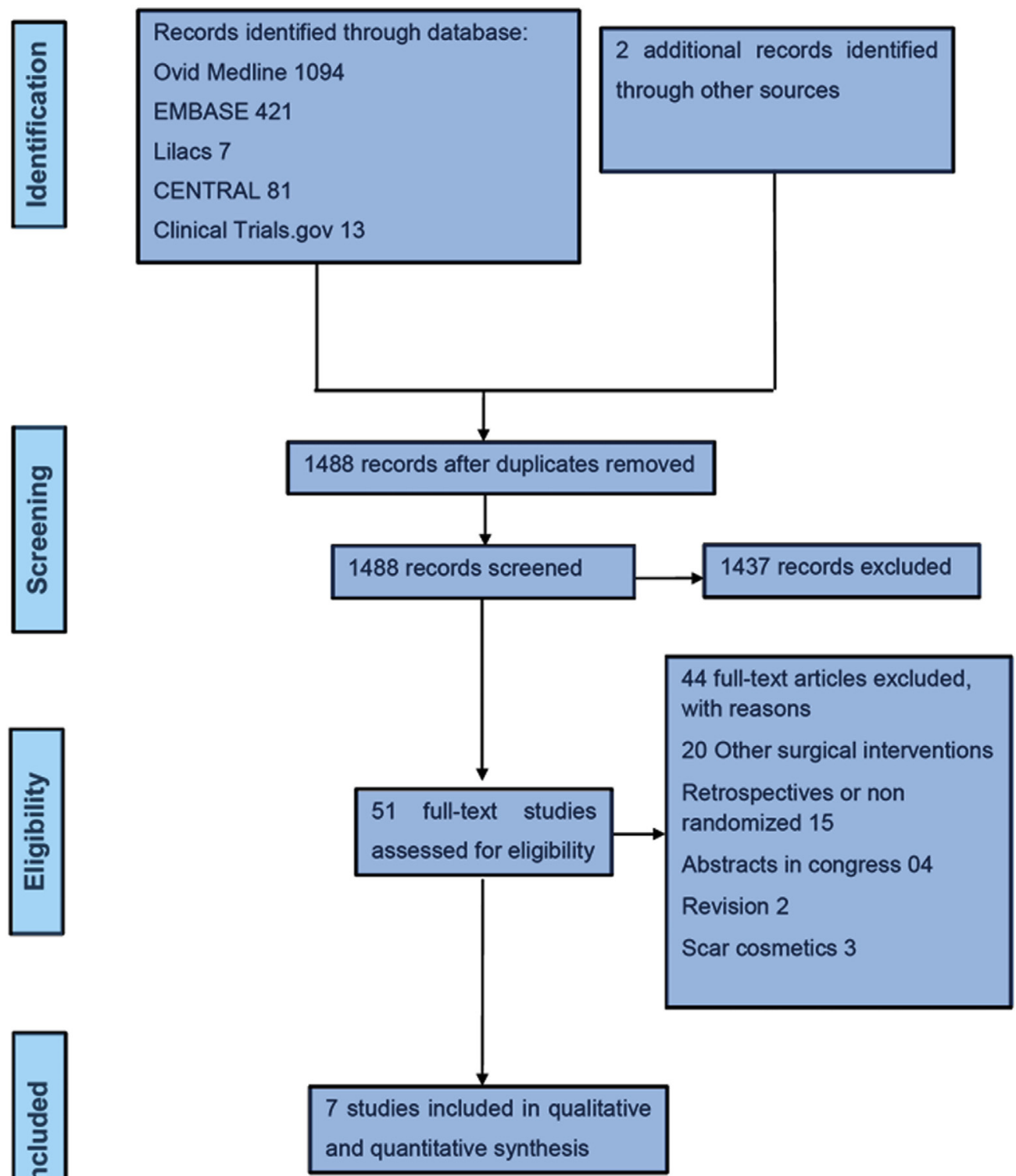

FIGURE 2. Flow diagram of screened and included articles.

Six studies involving 1936 people assessed this outcome. $^{10,11,15,16,18,19}$ Nonstandard closure makes little or no difference against standard closure on deep sternal wound infection (RR, 0.42; 95\% CI, 0.11-1.59; $\mathrm{I}^{2}=47 \%$ ) (Figure $3, A$ ). The quality of the evidence was low, downgraded because of inconsistency, selection bias, and detection bias.

2. Superficial wound infection

Four studies involving 1076 people assessed this outcome. ${ }^{11,15,16,18}$ Nonstandard closure makes little or no difference against standard closure on wound dehiscence (RR, 1.38; 95\% CI, 0.83-2.30; $\mathrm{I}^{2}=0 \%$ ) (Figure 3, B). The quality of the evidence was moderate downgraded because of selection bias and detection bias.

\section{Effects of interventions: Secondary Outcomes}

\section{Death}

Five studies involving 1210 people assessed this outcome. $^{11,16-19}$ Nonstandard closure makes little or no difference against standard closure on death (RR, 0.93; 


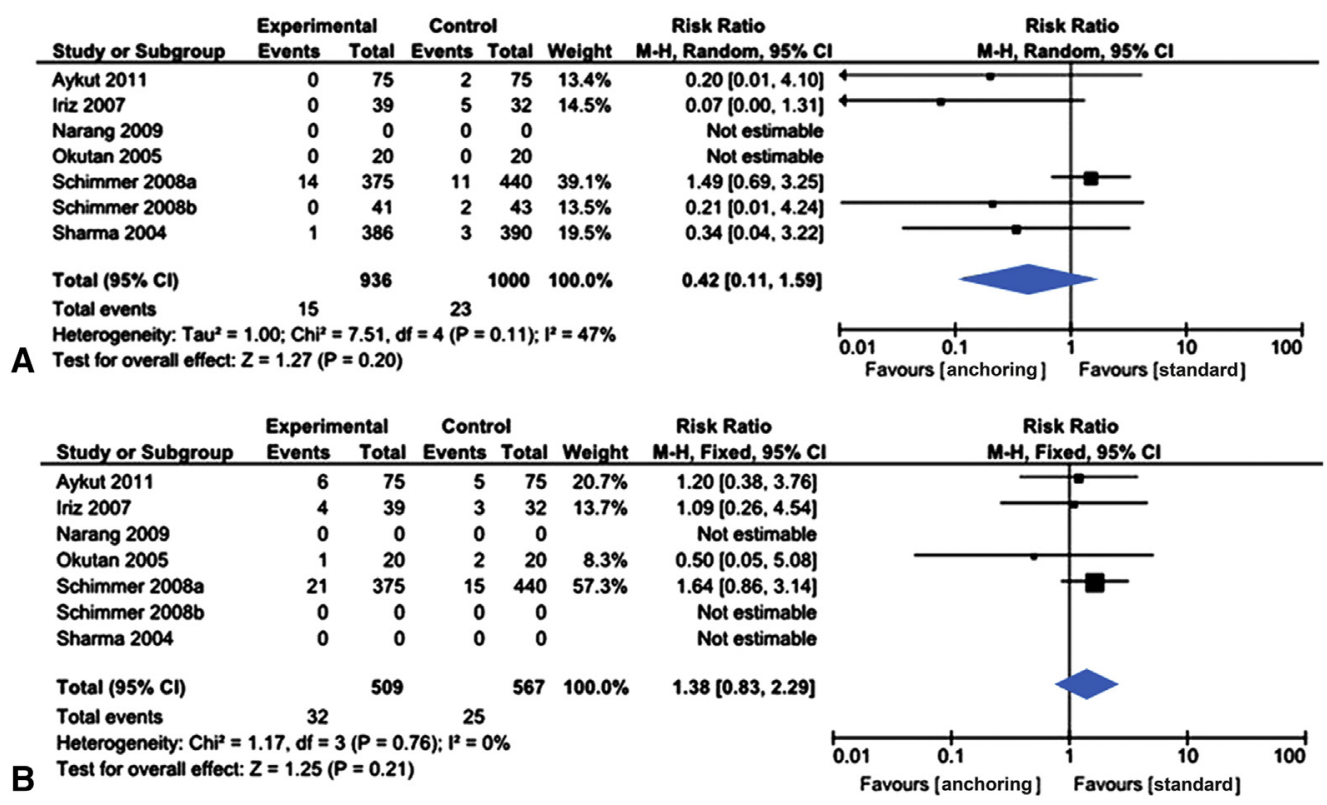

FIGURE 3. Forest plot of the RR in primary outcomes. A, Deep sternal wound infection, meta-analysis in 6 studies (RR, 0.42; 95\% CI, 0.11-1.59). B, Superficial wound infection, meta-analysis in 4 studies (RR, 1.38; 95\% CI, 0.83-2.29). $M-H$, Mantel-Haenszel; $C I$, confidence interval; $d f$, degrees of freedom.

95\% CI, 0.47-1.84; $\mathrm{I}^{2}=0 \%$ ) (Figure $4, A$ ). The quality of the evidence was moderate downgraded because of selection bias and detection bias.

\section{Sternal instability}

Five studies involving 1981 people assessed this

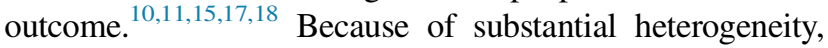
the meta-analysis for this outcome was considered inappropriate. In 3 studies, ${ }^{11,15,18}$ there was no difference between the 2 groups, but in 2 other studies ${ }^{10,17}$ sternal instability was lower in nonstandard closure. Nonstandard closure may make little or no difference on sternal instability. The quality of the evidence was low downgraded for inconsistency.

\section{Mediastinitis}

Four studies involving 1197 people assessed this outcome. $^{10,15-17}$ Nonstandard closure makes little or no difference against standard closure on mediastinitis (RR, 0.74; 95\% CI, 0.17-3.16; $\mathrm{I}^{2}=4 \%$ ) (Figure 4, B). The quality of the evidence was moderate downgraded because of selection bias and detection bias.

\section{Hospital stay}

Four studies involving 1010 people assessed this outcome. $^{11,16,18,19}$ Because of substantial heterogeneity, the meta-analysis for this outcome was considered inappropriate. In 2 studies, ${ }^{18,19}$ there was no difference between the 2 groups; in 1 study, ${ }^{16}$ hospital stay was lower in nonstandard closure: -5.8 fewer days $(95 \% \mathrm{CI},-9.34$ to -2.26$)$. One study ${ }^{11}$ presented mean without standard deviation:
7 days in standard and nonstandard closure. The quality of the evidence was low downgraded for inconsistency.

\section{Reoperation}

Three studies involving 434 people assessed this outcome. ${ }^{15,17,19}$ Nonstandard closure makes little or no difference against standard closure on reoperation (RR, $0.82 ; 95 \%$ CI, 0.34-1.98; $\mathrm{I}^{2}=0 \%$ ) (Figure 4, $C$ ). The quality of the evidence was moderate downgraded because of selection bias and detection bias.

\section{Mechanical ventilation time}

Two studies involving 899 people assessed this outcome. $^{18,19}$ Because of the substantial heterogeneity, the meta-analysis for this outcome was considered inappropriate. In 1 study, ${ }^{18}$ there was no difference between the 2 groups, but in the other study ${ }^{19}$ mechanical ventilation time was lower in nonstandard closure: 12 fewer hours (95\% CI, -16.76 to -7.24$)$. The quality of the evidence was low downgraded for inconsistency.

\section{Intensive care unit stay}

Only 1 study involving 815 people assessed this outcome. $^{18}$ There was no difference between groups (mean difference, $0.13 ; 95 \% \mathrm{CI},-0.52$ to 0.78 ).

\section{Pain}

Only 1 study involving 86 people assessed this outcome. ${ }^{19}$ This study presented results in the number and 


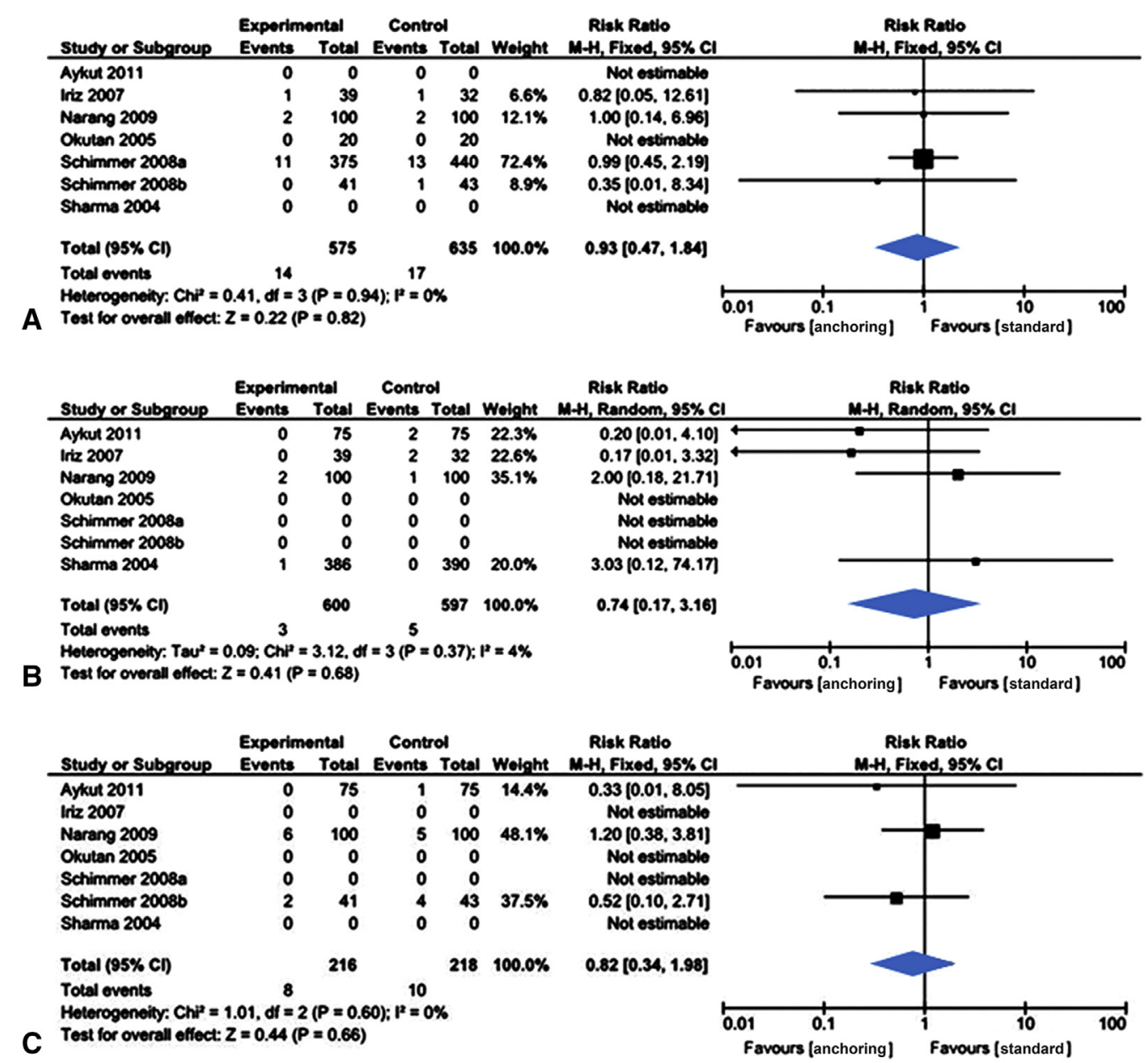

FIGURE 4. Forest plot of the RR in secondary outcomes. A, Death: meta-analysis in 5 studies (RR, 0.93; 95\% CI, 0.47-1.84). B, Mediastinitis: metaanalysis in 4 studies (RR, 0.74; 95\% CI, 0.17-3.16). C, Reoperation: meta-analysis in 3 studies (RR, 0.82; 95\% CI, 0.34-1.98). M-H, Mantel-Haenszel; $C I$, confidence interval; $d f$, degrees of freedom.

percentage of patients with chest pain more than 3 days without defining pain scores (standard closure $31[71 \%]$, nonstandard $21[52 \%] P=.04)$. Table 2 shows the summary of findings.

\section{DISCUSSION}

This review evaluates the effects of anchoring techniques of steel wires to avoid bone rupture in the prevention of sternal wound complications after sternotomy. Robicsek and colleagues ${ }^{9}$ described this technique in 1977 and used this method in 8 patients; in 5 of these cases, the aim was to prevent complications, and in the other 3 to correct existing complications (nonunion and infection). The authors reported satisfactory results for correction in patients in whom instability or infection had already occurred. Some authors simplified this technique, ${ }^{10}$ and others made it more complex. ${ }^{20} \mathrm{Be}$ sides increasing surgical time, this technique is not free of complications because it can lead to increased bleeding and pseudoaneurysms in the internal thoracic artery. ${ }^{21}$ This complication is rare and may occur in standard closure, but as in the Robicsek method more steel wires are passed, and the probability becomes greater.

This made us question whether it was valid to apply it in all patients at risk, leading us to carry out this review. Seven studies were included in this review, with a total of 2138 participants. The follow-up ranged from 3 to 16 months. Most studies analyzed the outcomes of interest but lacked a clear and precise definition of what they are. This made it difficult to combine some outcomes such as superficial wound infection (wound dehiscence), sternal instability (without infection), and mediastinitis. The overall quality of the evidence is moderate in most outcomes. The primary outcomes are based on 4 or 5 trials. However, it must be pointed out that this is the best available evidence on the topic. Evidence from isolated experimental or observational studies may be more uncertain, 
considering inconsistencies observed across included studies for various outcomes. There are more observational studies than RCTs in this topic because of the difficulties in conducting RCTs in surgical treatments, such as the inability to "blind" interventions, because they are visible; different skill levels of surgeons, that is, they may not conduct operations equally well; and unwillingness to undergo randomization by patients and surgeons and inability to force it. It can be seen that the high risk of bias occurred mainly in the blinding; also, there was not much rigor in the selection of patients and the blindness of the outcome assessors (selection and detection bias). The factors that may reduce the quality of the evidence in some outcomes are inconsistencies among studies, selection bias, detection bias, and small sample size. However, we believe that the combination of these studies can lead to better evidence than each individual study. Studies on sternal closure after sternotomy involve different alternative methods of closure, which hinder the combination of the studies. We have studied techniques that use steel wire anchoring methods so that they do not fracture the sternum, and of the 51 eligible studies we were able to include only 7 . We believe that our search has been sensitive so that we do not lose any RCT. This systematic review confirmed some of the findings of the isolated studies. In none of the isolated studies was there a significant difference between the 2 interventions on the outcomes: deep sternal wound infection ${ }^{10,11,15,16,18,19}$ and superficial wound infection. ${ }^{11,15,16,18}$ Narang and colleagues ${ }^{17}$ found a lower incidence of sternal instability in patients with anchoring techniques of steel wires (RR, $0.20 ; 95 \%$ CI, 0.04-0.89), but they found no sternal instability in patients with a single risk factor. In patients with 2 or more risk factors, the rate of sternal instability was $12.5 \%$ after routine wire closure and $2.5 \%$ after nonstandard closure. They concluded that routine sternal closure is sufficient in all patients with a single risk factor, whereas prophylactic anchoring techniques of steel wires should be performed in all high-risk patients (with $\geq 2$ risk factors) undergoing median sternotomy. According to the review published by Lazar and colleagues, ${ }^{22}$ "Closing a sternum with multiple fractures using the Robicsek weave technique may prevent sternal dehiscence and wound infection (Class IIa Recommendation; Level of Evidence = B)." Sharma and colleagues ${ }^{10}$ also found a lower incidence of sternal instability in patients with anchorage techniques than in routine sternal closure (RR, 0.06; 95\% CI, 0.01-0.47). Bottio and colleagues ${ }^{23}$ performed an RCT to test double crisscross sternal wiring techniques. In the 350 patients, the Robicsek technique was used and there were $1.7 \%$ of deep infections, a result similar to the one found in this review, and $2 \%$ of superficial infections, a value below the one found in this review, but not all patients were at risk.

\section{CONCLUSIONS}

This review showed moderate quality evidence (Table 2) that anchoring techniques of steel wires to prevent bone rupture (nonstandard) for the closure of median sternotomies (Robicsek original or modified or stapler) probably make little or no difference in relation to the standard closure in the postoperative period of patients with risk factors. The findings of this review can be applied to sternal closure in high-risk patients who will undergo elective cardiac surgery. These findings cannot be applied to reoperation for correction of sternum separation if it has already occurred.

\section{Conflict of Interest Statement}

Authors have nothing to disclose with regard to commercial support.

The authors thank all the investigators and patients who participated in the studies assessed in this review.

\section{References}

1. Tekümit H, Cenal AR, Tataroğlu C, Uzun K, Akinci E. Comparison of figure-ofeight and simple wire sternal closure techniques in patients with non-microbial sternal dehiscence. Anadolu Kardiyoloji Dergisi. 2009;9:411-6.

2. Landes G, Harris PG, Sampalis JS, Brutus JP, Cordoba C, Ciaburro H, et al. Outcomes in the management of sternal dehiscence by plastic surgery: a ten-year review in one university center. Ann Plast Surg. 2007;59:659-66.

3. Graeber GM, McClelland WT. Current concepts in the management and reconstruction of the dehisced median sternotomy. Semin Thorac Cardiovasc Surg. 2004; 16:92-107.

4. Losanoff JE, Jones JW, Richman BW. Primary closure of median sternotomy: techniques and principles. Cardiovasc Surg. 2002;10:102-10.

5. Molina JE, Lew RS, Hyland KJ. Postoperative sternal dehiscence in obese patients: incidence and prevention. Ann Thorac Surg. 2004;78:912-7.

6. Peivandi AA, Kasper-König W, Quinkenstein E, Loos AH, Dahm M. Risk factors influencing the outcome after surgical treatment of complicated deep sternal wound complications. Cardiovasc Surg. 2003;11:207-12.

7. Fedak PWM, Kieser TM, Maitland AM, Holland M, Kasatkin A, LeBlanc P, et al Adhesive-enhanced sternal closure to improve postoperative functional recovery: a pilot, randomized controlled trial. Ann Thorac Surg. 2011;92:1444-50.

8. Imren Y, Selek H, Zor H, Bayram H, Ereren E, Tasoglu I, et al. The management of complicated sternal dehiscence following open heart surgery. Heart Surg Forum. 2006;9:E871-5

9. Robicsek F, Daugherty HK, Cook JW. The prevention and treatment of sternum separation following open-heart surgery. J Thorac Cardiovasc Surg. 1977;73: 267-8.

10. Sharma R, Puri D, Panigrahi BP, Virdi IS. A modified parasternal wire technique for prevention and treatment of sternal dehiscence. Ann Thorac Surg. 2004;77: 210-3.

11. Okutan H, Tenekeci C, Kutsal A. The reinforced sternal closure system is reliable to use in elderly patients. J Card Surg. 2005;20:271-3.

12. Higgins JPT, Altman DG, Sterne JAC. Assessing risk of bias in included studies In: Higgins JPT, Green S, eds. Cochrane Handbook for Systematic Reviews of Interventions. Version 5.1.0 [updated March 2011]. Bethesda, MD: The Cochrane Collaboration; 2011:8. Available at: www.cochrane-handbook.org. Accessed June 27, 2017.

13. Deeks JJ, Higgins JPT, Altman DG. Analysing data and undertaking meta-analyses. In: Higgins JPT, Green S, eds. Cochrane Handbook for Systematic Reviews of Interventions. Version 5.1.0 [updated March 2011]. Bethesda, MD: The Cochrane Collaboration; 2011:9. Available at: www.cochranehandbook.org. Accessed June 27, 2017.

14. Guyatt GH, Oxman AD, Kunz R, Vist GE, Falck-Ytter Y, Schunemann HJ GRADE Working Group. What is 'quality of evidence' and why is it important to clinicians? BMJ. 2008;336:995-8. 
15. Aykut K, Celik B, Acıkel U. Figure-of-eight versus prophylactic sternal weave closure of median sternotomy in diabetic obese patients undergoing coronary artery bypass grafting. Ann Thorac Surg. 2011;92: 638-41.

16. Iriz E, Erer D, Koksal P, Ozdogan ME, Halit V, Sinci V, et al. Corpus sterni reinforcement improves the stability of primary sternal closure in high-risk patients. Surg Today. 2007;37:197-201.

17. Narang S, Banerjee A, Satsangi DK, Geelani MA. Sternal weave in high-risk patients to prevent noninfective sternal dehiscence. Asian Cardiovasc Thorac Ann. 2009; 17:167-70.

18. Schimmer C, Reents W, Berneder S, Eigel P, Sezer O, Scheld H, et al. Prevention of sternal dehiscence and infection in high-risk patients: a prospective randomized multicenter trial. Ann Thorac Surg. 2008;86:1897-904.
19. Schimmer C, Sommer SP, Bensch M, Bohrer T, Aleksic I, Leyh R. Sternal closure techniques and postoperative sternal wound complications in elderly patients. Eur J Cardiothorac Surg. 2008;34:132-8.

20. Lafci G, Yasar E, Cicek OF, Irdem A, Uzun A, Yalcinkava A. A novel modified Robicsek technique for sternal closure: "Double-check". Asian Cardiovasc Thorac Ann. 2014;22:758-60.

21. Albarran AA, González JAB, Cabrero TH, Villegas EG. Internal mammary artery pseudoaneurysm following a Robicsek sternal closure. J Card Surg. 2017;32:264-5.

22. Lazar HL, Salm TV, Engelman R, Gordom S. Prevention and management of sternal wound infections. J Thorac Cardiovasc Surg. 2016;152:962-72.

23. Bottio T, Rizzoli G, Vida V, Casarotto D, Gerosa G. Double crisscross sternal wiring and chest wound infections: a prospective randomized study. J Thorac Cardiovasc Surg. 2003;126:1352-6. 